\title{
Comparativo dos benefícios das Redes Sociais para a educação empreendedora com base em es- tudo qualitativo com empreendedores locais
}

Cavalcanti, J. A.

Escola Politécnica de Pernambuco Universidade de Pernambuco 50.720-001 - Recife, Brasil jheymesson.c@mail.com
Cruz Neto, G. G.

Escola Politécnica de Pernambuco

Universidade de Pernambuco

50.720-001 - Recife, Brasil

genesio@ecomp.com..br

Resumo Empresas de sucesso estão reconhecendo e privilegiando cada vez mais profissionais com características empreendedoras. Por isto, a educação empreendedora hoje passa a ter um papel fundamental na formação dos jovens, apesar de existirem ainda poucas metodologias educacionais voltadas ao incentivo da criatividade e da autonomia dos alunos. Em paralelo, a sociedade mundial vivenciou nos últimos anos uma revolução causada pelo surgimento da internet e suas redes sociais. Este artigo apresenta uma análise comparativa entre as redes sociais mais usadas em relação às suas potencialidades para o empreendedorismo, tendo como base um estudo qualitativo feito com empreendedores locais. O objetivo foi de traçar requisitos que possam melhorar a rede social "Células Empreendedoras", uma rede em formação especificamente voltada para a educação empreendedora de jovens e professores universitários.

\footnotetext{
Abstract Successful companies are recognizing and focusing more and more professionals with entrepreneurial characteristics. Therefore, entrepreneurial education today is to have a key role in educating the young, although there are still few educational methodologies aimed at encouraging creativity and autonomy of students. In parallel, the global society in recent years experienced a revolution caused by the emergence of the Internet and their social networks. This article presents a comparative analysis of social networks commonly used in relation to their potential for entrepreneurship, based on a qualitative study done with local entrepreneurs. The objective was to trace requirements that may improve the social network "cells Entrepreneurs", a network training specifically for the education of youth and entrepreneurial academics.
} 


\section{Introdução}

Para Dolabela (1999), os empreendedores criam um novo modelo de sistemas de valores na sociedade, onde os comportamentos individuais dos seus participantes são fundamentais, portanto, a ação do empreendedor é a base do desenvolvimento econômico. Num mercado cada vez mais competitivo, as empresas passam a exigir de seus profissionais características empreendedoras.

Por esta razão a educação empreendedora passa a ter um papel fundamental na formação do ensino superior. No entanto, pouco se observa o uso de metodologias educacionais voltadas ao incentivo da criatividade e da autonomia dos jovens nas faculdades e universidades brasileiras [Santos 2010].

Em paralelo, a sociedade mundial vivenciou nos últimos anos uma revolução social causada pelo surgimento da internet e suas redes colaborativas (www.gilgiardelli.com.br). "As novas mídias sociais estão permintindo o surgimento de ações conjuntas de mudança social, estamos em uma nova era de generosidade e criatividade coletiva" [Giardelli 2010].

Novas ferramentas de colaboração surgem a cada dia para efetivação da aprendizagem [Machado e Tijiboy, 2005; Gomes, Martins e Melo 2010]. Ambientes virtuais educativos baseadas em blogs e redes sociais estarão cada vez mais disponíveis para uso por parte de professores e alunos.

No entanto, constata-se que os modelos educacionais de formação empreendedora trabalhados atualmente nas instituições de ensino focam-se muitas vezes apenas na operacionalização de planos de negócios, e pouco atuam nas questões comportamentais associadas a criatividade, autonomia e atividadades socioculturais.

Este artigo apresenta uma análise comparativa entre as redes sociais mais usadas em relação às suas pontencialidades para o empreendedorismo e a educação empreendedora, tendo como base um estudo qualitativo feito com empreendedores locais. O objetivo foi de traçar requisitos que possam melhorar a rede social "Células Empreendedoras", uma rede em formação especificamente voltada para a educação empreendedora de jovens e professores universitários [www.celulasempreendedoras.com.br].

A pesquisa qualitativa realizada teve como base o método Grounded Theory [Strauss e Corbin 1998]. O mesmo foi inicialnente usado como método de elictação de requisitos nos trabalhos da tese de doutorado do co-autor deste artigo [Cruz Neto, Gomes e Castro 2005; Cruz Neto, Gomes e Oliveira 2007; Cruz Neto, Gomes e Castro 2008; Cruz Neto 2008].

\section{Comportamento Empreendedor \& as Redes Sociais}

O SEBRAE (Sebrae 2011), um dos maiores órgãos do Brasil de apoio ao empreendedor, fez um estudo colocando em evidência 10 competências básicas do empreendedor e que são ressaltadas por Leite (2002) e por MARIANO (2008), são elas:

1. Busca por oportunidades e iniciativas;

2. Persistência;

3. Comprometimento;

4. Exigência na qualidade e na eficiência;

5. Saber correr ricos calculados;

6. Planos e metas;

7. Busca por informações;

8. Planejamento e monitoramento;

9. Persuasão e rede de contatos;

10. Independência e auto-confiança.

A maioria dos autores de livros sobre empreendedorismo, como Dolabella (1999), não divergem dessas competências, assim é muito importante a valorização e a acepção das mesmas. Cada pessoa tem suas próprias características e o mais importante é desenvolver as competências que já possui e aos poucos ir adquirindo as demais. O projeto das Células Empreendedoras, por exemplo, promove as seguintes competências básicas citadas na lista: busca por oportunidades e iniciativas (1), persistência (2), comprometimento (3), planos e metas (6), busca por informações (7), planejamento e monitoramento (8), rede de contatos (9) e auto-confiança (10).

A característica que o projeto mais visa desenvolver é a auto-confiança, através de encontros presenciais para troca de informações e conhecimentos de forma colaborativa com pessoas que vivem a mesma realidade e buscam empreender seus sonhos de vida profissional. Através desses encontros o projeto cresce a cada dia e com os resultados fica cada vez mais evidente que o mesmo tem colaborado para o desenvolvimento de diversos jovens empreendedores. 
A ação do empreendedor é a base do desenvolvimento econômico e as redes sociais estão fazendo parte de um recurso indispensável para o empreendedor, pois alem de um grande volume de troca de informações, fortalece sua rede de contatos de uma forma muito eficiente.

Para Dornelas (2001) os empreendedores são

1) visionários, indivíduos que fazem a diferença,

2) sabem explorar as oportunidades, são determinados e dinâmicos,

3) dedicados ao trabalho, otimistas e apaixonados pelo que fazem,

4) independentes e construtores do próprio destino,

5) acreditam que o dinheiro é conseqüência do sucesso nos negócios,

6) possuem liderança incomum,

7) sabem construir uma rede de relacionamentos externos à empresa,

8) planejam cada passo do negócio, possuem conhecimento,

9) assumem riscos calculados e

10) criam valor para a sociedade, criando soluções para melhorar a vida das pessoas.

As redes sociais vêm crescendo muito nesses últimos anos, e o seu valor diante da sociedade e de seus grupos aumenta consideravelmente a cada dia. Elas têm se mostrado uma excelente ferramenta, tanto para a comunicação com pessoas do mesmo grupo social, como para o crescimento de cada empreendedor e a projeção de suas idéias para os outros, como referenciado pelo empreendedor Roberto Dantas (codinome) na pesquisa qualitativa realizada:

\section{"é muito importante você definir uma coisa que você quer, e a rede social permite com uma maior facilidade você projetar os seus sonhos para outras pessoas."; "Ela ajuda na melhor qualidade do empreendedor, que é a conexão social.".}

Assim, uma rede social que integre empreendedores e empresas torna-se um veículo fundamental na formação empreendedora. O projeto de pesquisa aqui proposto visa dar alguns passos para ume melhor concepção desta tecnologia.
Tendo em mente a importância das redes sociais para o empreendedor, faz-se apropriado um estudo sobre as mesmas, no tocante a como elas influenciam positivamente a atividade empreendedora. Para esse trabalho, foram selecionadas as seguintes redes sociais: o Facebook [www.facebook.com.br], o Orkut [www.orkut.com.br], a REDU Rede Social Educacional [www.redu.com.br] e a o projeto Células Empreendedoras [www.celulasempreendedoras.com.br];

A REDU tem como objetivo o ensino de maneira colaborativa, a rede social das células empreendedoras, por sua vez, tem um foco voltado a educação empreendedora de jovens e professores do ensino superior. Colaborativo. Facebook é a rede social que mais acessada no mundo e o Orkut por ser a mais acessada no Brasil segundo a pesquisa da Google e da Alexa, realizada em dezembro de 2010 (ver figura 01). O gráfico mostra em cores as redes mais usadas no mundo.

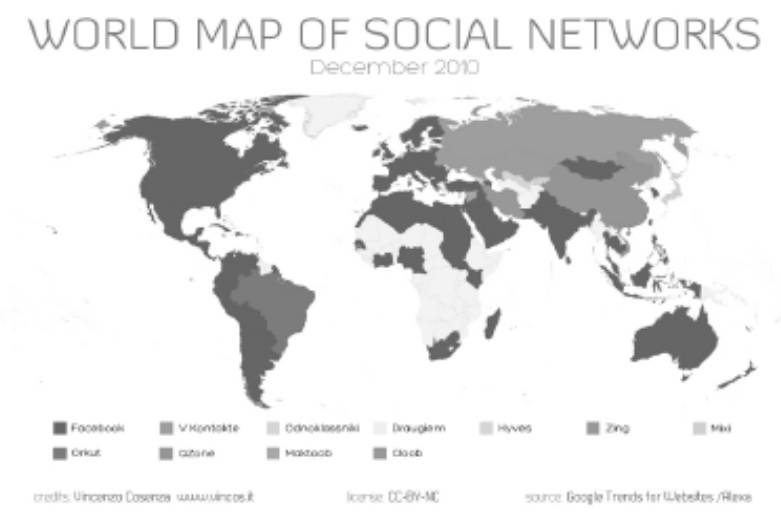

Figura 01: Análise das redes sociais mais usadas no mundo

Fonte: Google Trends for Websites e a Alexa.

\section{Pesquisa Qualitativa}

A pesquisa qualitativa surgiu como um questionamento à obtenção de uma "verdade absoluta" sobre os fenômenos. Pesquisadores qualitativos consideram que a realidade social depende dos atores que a sustentam, por isto o conhecimento que dela podemos obter é uma construção social desses atores [Denzin e Lincoln 1998]. Assim a procura de uma representação exata da realidade é questionável.

Pesquisas qualitativas sobre atividades humanas têm uma longa história de aplicação nas disciplinas humanas da Sociologia, Antropologia, Educação, entre outras. A palavra qualitativa implica o uso de processos e significados que não são examinados (ou mensurados) em termos de 
quantidade, grandeza, intensidade ou frequência. Os aspectos essenciais da pesquisa qualitativa consistem na escolha correta de métodos e teorias oportunos, na análise de diferentes perspectivas, nas reflexões dos pesquisadores a respeito de sua pesquisa como parte de um processo de produção de conhecimento, e na variedade de abordagens e métodos usados [Denzin e Lincoln 1998].

Neste caso, o objetivo não é criar modelos universais da realidade, mas construir uma representação comum que promova o diálogo e permita melhor compreender as percepções próprias e dos outros [Ramos 2000]. Existe na pesquisa qualitativa um intuito de questionar conceitos $\mathrm{e}$ práticas para explorar e compreender os fenômenos na sua totalidade. Por isto, a validade das representações restringe-se a determinado contexto.

Métodos quantitativos de pesquisa foram originalmente desenvolvidos nas ciências naturais para estudar fenômenos da natureza. Já os métodos qualitativos foram criados nas ciências sociais para permitir os pesquisadores estudarem os fenômenos sociais e culturais. Por isto, métodos qualitativos são projetados para ajudar os pesquisadores a entender as pessoas e seus contextos sociais e culturais [Myers 1997].

$\mathrm{Na}$ área de Engenharia de Requisitos, o contexto social e organizacional de um futuro sistema de software precisa ser compreendido de forma exploratória, em sua ampla complexidade. Sabe-se, no entanto, que o objetivo do entendimento de um fenômeno do ponto de vista do usuário e seu contexto social e institucional é largamente perdido quando os dados do campo são quantificados. A pesquisa quantitativa, com seus direcionamentos a verificação de hipóteses pré-definidas, faz com que as circunstâncias e contextualizações do fenômeno deixem de ser analisadas e observadas [Flick 2004].

A pesquisa qualitativa adota métodos mais abertos que façam justiça à complexidade do objeto de estudo. $\mathrm{O}$ fenômeno que se busca compreender (no caso o papel da tecnologia nas práticas diárias) não é reduzido a variáveis únicas, mas sim estudado em sua complexidade e totalidade em seu contexto diário [Flick 2004]. Portanto, os campos de estudo não são situações artificiais de laboratório, mas as práticas e interações dos sujeitos na vida cotidiana. A meta da pesquisa é procurar ir além o que já é bem conhecido para descobrir o novo e desenvolver conhecimentos empiricamente embasados [Strauss e Corbin 1998].

Utiliza-se o princípio da abertura para aumentar a complexidade incluindo o contexto onde o fenômeno ocorre. Neste caso, a estruturação teórica do assunto em estudo é construída através do contato com as pessoas que estiveram sendo estudadas. Assim, postula-se que o pesquisador deva, ao menos, suspender o conhecimento teórico a priori que ele traz ao campo [Flick 2004].

\subsection{Grounded Theory}

Grounded Theory é uma metodologia qualitativa, fundamentada no interpretativismo, que vem sendo progressivamente mais utilizada pelos investigadores no âmbito das ciências sociais e humanas [Fernandes e Maia 2001], como também na área de pesquisa em Sistemas de Informações [Myers 1997; Orlinkowki 1993; Scott 1998; Pandit 1998]. Em particular ela tem sido utilizada a mais de 20 anos desde o trabalho de Suchman (1987) na área de Interação Homen-Computador e Trabalho Colaborativo Suportado por Computador.

A idéia básica da Grounded Theory é ler (e re-ler) um banco de dados textuais (tais como, notas de observações de campo e/ou transcrições de entrevistas) para "descobrir" ou nomear variáveis (chamadas categorias, conceitos e propriedades) e seus relacionamentos, e partir daí construir uma explanação ("teoria") sobre o fenômeno. É uma abordagem que dá preferência aos dados e ao campo de estudo, em contraste as suposições pré-concebidas, que não devem ser aplicadas ao sujeito que está sendo estudado. As teorias devem ser "descobertas" e formuladas ao lidar com o campo e os dados empíricos a serem encontrados.

Um dos objetivos centrais dos idealizadores da Grounded Theory [Strauss e Corbin 1998] era de oferecer uma metodologia de pesquisa não especulativa, cuidadosamente legitimada, de modo a combater o estatuto desvalorizado que as metodologias qualitativas tinham por não garantirem uma verificação adequada [Glaser e Strauss 1967]. Por isso dedicaram um espaço considerável às questões de verificação, salientando aspectos como credibilidade, plausibilidade e confiança que devem ser assegurados pelos cuidados dos pesquisadores em cada passo.

Uma teoria, na Grounded Theory, é o resultado que oferece um sentido, ou significado, coerente para um conjunto de dados "brutos" (ex.: notas de campo e transcrições de entrevistas) sobre determinado fenômeno. Importante ressaltar que uma "teoria", neste caso, difere-se de um referencial teórico, como a Teoria da Atividade, que oferece um conjunto de construtores pré-definidos para o entendimento de práticas humanas.

Teoria, segundo a Grounded Theory, são conceitos construídos a partir da interpretação dos dados coletados de uma dada situação, e não um "modelo" (ou "receita") que pode ser aplicada para a descrição de várias situações. 


\section{Pesquisa Qualitativa Realizada}

A pesquisa qualitativa aqui realizada foi baseada no uso da Grounded Theory como forma de elicitação de requisitos [Cruz Neto 2008].

A pergunta de pesquisa usada como ponto focal de todo o trabalho foi: "quais os benefícios das redes sociais para a formação dos empreendedores". A partir da motivação em responder esta pergunta central, foram elaborados entrevistas iniciais com um conjunto de questões abertas a serem respondidas por empreendedores locais. Os empreendedores entrevistados seriam incentivados a falarem de tópicos quaisquer associados ao tema, as perguntas serviriam apenas para um direcionamento inicial. A partir do resultado das primeiras entrevistas novas questões eram introduzidas. O roteiro das entrevistas realizadas está no apêndice A. Foram 4 empreendedores entrevistados. Segue dados sobre os mesmos, bem como os codnomes usados para referenciá-los.

Tabela 01: Codinome, idade e experiência dos empreendedores entrevistados

\begin{tabular}{|c|c|c|c|}
\hline Codinome & $\begin{array}{l}\text { Idade } \\
\text { (anos) }\end{array}$ & $\begin{array}{l}\text { Experiência } \\
\text { (anos) }\end{array}$ & $\begin{array}{c}\text { Atividade } \\
\text { como } \\
\text { empreended } \\
\text { or }\end{array}$ \\
\hline $\begin{array}{l}\text { Carlos } \\
\text { Ricardo }\end{array}$ & 33 & 16 & $\begin{array}{l}\text { Pesquisador } \\
\text { de empresa } \\
\text { de software }\end{array}$ \\
\hline $\begin{array}{l}\text { Armando } \\
\text { Passos }\end{array}$ & 27 & 9 & $\begin{array}{l}\text { Gerente de } \\
\text { gravadora }\end{array}$ \\
\hline $\begin{array}{l}\text { Rodolfo } \\
\text { André }\end{array}$ & 22 & 7 & $\begin{array}{l}\text { Gerente de } \\
\text { empresa que } \\
\text { desenvolve } \\
\text { portais, com } \\
\text { redes sociais } \\
\text { embutidas }\end{array}$ \\
\hline $\begin{array}{l}\text { Roberto } \\
\text { Dantas }\end{array}$ & 25 & 6 & $\begin{array}{l}\text { Executivo } \\
\text { global na } \\
\text { China e } \\
\text { gerente de } \\
\text { empresa que } \\
\text { desenvolve } \\
\text { jogos para } \\
\text { redes sociais. }\end{array}$ \\
\hline
\end{tabular}

As entrevistas foram agrupadas e analisadas qualitativamente com auxilio do programa NVIVO (versão 2.0) [www.qsrinternational.com]. As entrevistas foram codificadas seguindo a metodologia Grounded Theory e organizadas em forma de arvore (figura 02), facilitando, dessa forma, a visualização de todas as entrevistas e seus pontos chaves para o levantamento dos requisitos. A Tabela 03 contém um descritivo de todas as ferramentas usadas.

Figura 02: Codificação resultante

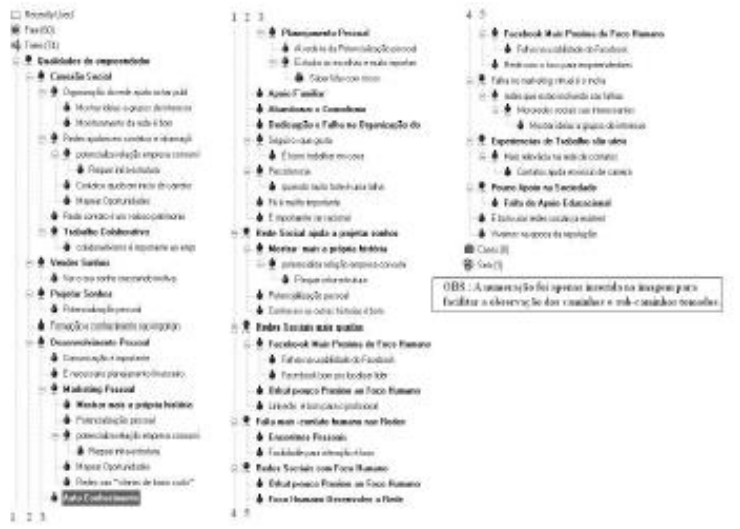

Tabela 02: Ferramentas utilizadas

\begin{tabular}{|c|c|c|}
\hline Tarefa & Ferramenta & $\begin{array}{l}\text { Endereço } \\
\text { Eletrônico }\end{array}$ \\
\hline Coleta & $\begin{array}{l}\text { Celular Nokia } \\
\text { (funcionalidad } \\
\text { e de midia, } \\
\text { gravação) }\end{array}$ & \\
\hline $\begin{array}{l}\text { Transcriç } \\
\text { ão }\end{array}$ & $\begin{array}{l}\text { Editor } \\
\text { Texto: } \\
\text { WORD }\end{array}$ & $\begin{array}{l}\text { www.microsoft. } \\
\underline{\text { com.br }}\end{array}$ \\
\hline $\begin{array}{l}\text { Análise } \\
\text { dos } \\
\text { Dados }\end{array}$ & $\begin{array}{l}\text { Software } \\
\text { NVTVO } 2.0\end{array}$ & $\begin{array}{l}\text { www.qsrinterna } \\
\text { tional.com }\end{array}$ \\
\hline \multirow[t]{2}{*}{$\begin{array}{l}\text { Document } \\
\text { ação }\end{array}$} & $\begin{array}{l}\text { Editor de } \\
\text { Texto: MS- } \\
\text { WORD (versão } \\
2007 \text { ) }\end{array}$ & $\begin{array}{l}\text { www.microsoft. } \\
\text { com.br }\end{array}$ \\
\hline & $\begin{array}{l}\text { Tratamento das } \\
\text { Imagens: MS- } \\
\text { Paint (presente } \\
\text { na } \\
\text { configuração } \\
\text { do Windows - } \\
\text { edição XP) }\end{array}$ & $\begin{array}{l}\text { www.microsoft. } \\
\text { com.br }\end{array}$ \\
\hline
\end{tabular}

Os resultados do estudo qualitativo estão distribuídos nos seguintes tópicos a serem abordados nas próximas sessões: 1) Relevância de uma educação empreendedora 2) Requisitos para redes sociais oriundos da pequisa qualitativa com empreendedores 3) Comparativo de redes sociais com base na pesquisa qualitativa 


\section{Relevância das Redes Sociais na Educação Empreendedora}

Empreendedores que não são associados ao projeto Células Empreendedoras relatam a falta de apoio obtido por parte das universidades para sua educação empreendedora , como citado pelo empreendedor Roberto Dantas (codinome):

\footnotetext{
"Pesquisador: A sua educação, em que ela foi útil na sua carreira como empreendedor?

Empreendedor: Não influenciou em nada. As pessoas que você encontra lá só sabem dizer que nada vai ser bom para você, até minha coordenadora, quando eu a encontro hoje ela diz que nunca imaginava que eu iria chegar tão longe. Eu lembro mesmo de professoras minhas, me falando que eu não ia aprender educação empreendedora.

"Estudante: No caso, ao invés deles influenciar eles desmotivam. Empreendedor: É e eles desmoralizam.";
}

Alguns dados comprovam isto. Segundo pesquisa do Global Entrepreneurship Monitor realizada em 2000, tendo sido entrevistadas 43.000 pessoas em 21 países para cada 8 brasileiros em idade adulta, 1 estava abrindo ou pensando em abrir um negócio. Colocando o Brasil em $1^{\circ}$ lugar no campeonato mundial do espírito empreendedor, em $2^{\circ}$ lugar os EUA na proporção de 10 para 1 e em $3^{\circ}$ lugar a Austrália na proporção de 12 para 1 [Sebrae 2005]. Por outro lado, segundo estudo do Banco Mundial, o Brasil faz feio em matéria de apoiar os empreendedores, de 155 países listados o Brasil está na $119^{\mathrm{a}}$ posição, atrás de seus principais competidores emergentes como México $\left(73^{\mathrm{a}}\right)$, Rússia $\left(79^{a}\right)$ e China(91ª $)$ [GEM 2000].

As redes sociais estão mudando esta realidade, pois elas auxiliam em sua qualidade mais importante segundo o empreendedor Roberto Dantas (codinome): "Ela ajuda na melhor qualidade do empreendedor, que é a conexão social. "; O projeto Células Empreendedoras, por exemplo, tem sua própria rede social em seu portal (www.celulasempreemdedoras.com.br) e não só visando o apoio em rede social, como também visando encontros presenciais que completam a rede social. Segue relatos que justificamo uso de Redes Sociais por parte dos empreendedores:

\footnotetext{
"E porque as pessoas precisam mostrar mais que elas se conhecem, tanto individualmente como pessoalmente" (Roberto Dantas),
}

$$
\begin{aligned}
& \text { “acho que antes de qual quer coisa } \\
& \text { que você for fazer algo que vá } \\
& \text { demandar muito tempo, ou algo que vá } \\
& \text { demandar a vida inteira, você precisa } \\
& \text { se conhecer bem para poder iniciar, aí } \\
& \text { depois disso você começa a ver como } \\
& \text { as pessoas se conhecem (umas as } \\
& \text { outras) e como as pessoas se conhecem } \\
& \text { (conhecem a si mesmas), a partir disso } \\
& \text { você deve ver como é o vínculo entre } \\
& \text { as pessoas" (Armando Passos) e: "Não } \\
& \text { é rede social em si, eu estou querendo } \\
& \text { propor encontros pessoais, acontece } \\
& \text { muito na Europa e na Ásia, uma vez } \\
& \text { por mês eles tem mais interação, } \\
& \text { marcam uma festa e mostram } \\
& \text { trabalhos pessoais" (Roberto Dantas). }
\end{aligned}
$$

\section{Requisitos para redes sociais volta- das ao empreendedorismo}

A partir da análise qualitativa das entrevistas com base no método Grounded Theory, foram identificados quais os requisitos que as redes sociais deveriam possuir para serem adequadas ao universo do empreendedorismo segundo os empreendedores entrevistados. Segue resultados por áreas.

\subsection{Requisitos sobre Organização das infor- mações disponíveis na Rede Social}

A rede social deve ser organizada e estruturada por tópicos de interesse no tocante a obtenção de informação, bem por grupos específicos de pessoas, como referidos pelos empreendedores abaixo relacionados. É relevante a organização das informações disponíveis.

Carlos Ricardo: "Acho que falta um pouco de estrutura, porque assim, o conceito de rede social, foi feito com base em

liberdade, então é você deixar livre para que as pessoas se comuniquem e se relacionem, o LinkedIn tem um pouco disso de se estruturar e você, de você criar comunidades especificas de determinados tópicos e de você trabalhar em cima daqueles tópicos, então eu acho que se você tivesse uma organização estruturada, onde o usuário poderia estar buscando a informação de forma segmentada, conforme o tipo de interesse que ele tem em determinado assunto, coisas do tipo,você fazer cruzamento de interesses, e de poder perceber a partir de tecnologia e de inteligência computacional usuários que tenham preferência ou interesses 
relacionados ao meu, aí você traria ferramentas que pudessem servir ao empreendedor, porque, ele estaria de certa forma, ele estaria tendo uma facilidade para encontrar o mercado dele...";

Armando Passos: "Acho que é mais a questão de mostrar o trabalho pessoal, e encontrar o seu publico alvo, porque como é dividida em grupos e subgrupos

e tal, e comunidades, isso facilita muito...Verdade, a organização ajuda

bastante para você achar o publico alvo."; e: "porque você recebe de tudo, esse é o problema do marketing virtual...então você não recebe coisas que lhe interessam, mas você recebe 500 coisas em que 1 vai te interessar, aí você apaga todo o "sumario" mesmo, você não vai ficar perdendo tempo lendo tudo.;

Rodolfo André: “...O Ning é uma rede social que você cria a sua rede social, então você pode ter uma rede social por exemplo, partindo da escola de redes, que é uma rede social de quem trabalha estudando redes sociais, que tem 6 mil pessoas, mas que ela está no ar a mais de 5 anos, 6 mil pessoas, mas são 6 mil pessoas que o que une elas é um assunto, então elas se comunicam, e quando eu abro o meu Ning para ler, geralmente tudo o que está ali me interessa...".

\subsection{Sobre o monitoramento da rede social}

Também é interessante que haja um monitoramento das redes sociais tanto pela parte da pessoa que a usa como da parte da equipe que desenvolve e adapta a rede.

Carlos Ricardo: "você quer um monitoramento da rede, então tem uma ferramenta que agente desenvolveu que ela faz isso nas principais redes sociais, ela faz um monitoramento on-line de tudo o que está acontecendo na rede sobre um assunto que você tem interesse e vai consolidando isso em gráfico, mas enfim, é um serviço que a gente provê pro mercado, e o que eu estou dizendo é que as próprias redes sociais elas poderiam estar provendo esse serviço, mas isso não é algo que é comum hoje em dia, porque o propósito da rede social é outro, é deixar ali e fazer com que o ambiente seja favorável à comunicação e pouco intrusivo.".

\subsection{Sobre acesso as histórias de uns aos ou- tros}

É relevante que as pessoas conheçam a história doempreendedor, de como o mesmo se desenvolveu, bem como exemplos de sucessos e fracassos de outros empreendedores. Estas informações acrescentam o desenvolvimento dos empreendedores no mercado em que atuam.

Roberto Dantas: “...fazer com que as pessoas conheçam mais a minha história e passem a me ver dessa forma.";

Carlos Ricardo: “Colocaria casos, eu colocaria cases de empreendedores de sucesso e de insucesso, eu deixaria isso bem, bem... Visível, porque assim, você tem muito livro, muita bibliografia de empreendedorismo e que assim, todo mundo sabe que o empreendedorismo o cara tem que montar um plano de negócios, tem que passar por algumas etapas; mas a experiência pessoal das pessoas não está disponível em literatura, muito pouco é disponível, e o que é de mais interessante é isso, porque a literatura de uma maneira geral já expõe os passos pra você maximizar o sucesso.".

\subsection{Sobre foco no mercado de trabalho}

É interessante que as redes sociais tenham em seu ambiente um espaço próprio para currículos, com um foco profissional mais definido e claro. Neste ponto a rede social que mais se destaca é a LinkedIn, que não foi analisada.

Carlos Ricardo: “...Eu uso muito o LinkedIn, é primeiro porque, lá eu vejo que, para o tipo de trabalho que eu desenvolvo de negócio e também para os estudos que eu faço em pesquisa, para evolução de serviços e produtos que eu desenvolvo, ele traz beneficio...";

Rodolfo André: "o LinkedIn eu acredito que hoje é um "deus do currículo online", poderia chamar assim, você lá se expõe à empresas e você vai receber propostas de trabalho pelo LinkedIn, $e$ também eu procuro pessoas para 
trabalhar no LinkedIn, porque lá, por exemplo, você indica um amigo seu, você diz que já trabalho com ele, que ele é “assim, é assado", ai outra pessoa que não gostou de trabalha com ele vai lá e fala que não gostou de trabalhar com ele e por que ele é “assim, assado”, então se cadastrar no LinkedIn é uma aventura, pode dar certo ou pode dar muito errado, então eu uso o LinkedIn nesse ambiente profissional".

\subsection{Sobre a rede socialde trabalho}

É muito importante que a rede social seja intuitiva, com uma boa usabilidade.

\section{Armando Passos: "agora as dificuldades do Facebook inicialmente é o primeiro impacto, eu usava muito Orkut, o MySpace e quando eu fui migrar para o Facebook, foi inevitável, eu tive muito impacto com a utilização, ou seja, a usabilidade não é uma coisa boa no Facebook, você aprende o programa, não fica restrito e tal mas não é fácil de pegar essas utilidades de primeira.";}

Deve-se observar que os usuários que entram em diversas redes sociais ao mesmo tempo. No momento eu que exista falhas de usabilidade, a tendência é que a pessoa resista ao uso de uma em pró da concorrente.

\subsection{Sobre a rede socialde trabalho}

Armando Passos: "Eu acho que seria interessante fazer uma rede social de empreendedores.";

Rodolfo André: "eu acho que é o que é exclusivo...Já atrai as pessoas que querem ser empreendedoras.", e “...eu agora não estou falando com uma multidão, eu estou falando com um amigo, o principal que atrai é a exclusividade, eu comparo muitas coisas com relacionamento e com esportes, $o$ que atrai uma pessoa ao outro no relacionamento realmente é a exclusividade, não é o diferencial, e que ele é exclusivo, é exclusivamente ela, e eu acho que cada rede social, pra crescer, ela vai ter que ser exclusivamente ela...".

\subsection{Sobre a evolução da rede social}

O desenvolvimento da rede social deve ser dinâmico. O ideal é que a rede social esteja sempre em mutação com um constante processo de comunicação com as pessoas que a utiliza e a equipe de desenvolvimento.

$$
\begin{aligned}
& \text { Armando Passos: “...tipo a demanda das } \\
& \text { pessoas diz exatamente o que elas vão } \\
& \text { querer então você deve estar andando } \\
& \text { junto com o pessoal que está utilizando a } \\
& \text { rede social.", e "Quem faz não pode } \\
& \text { ditar como é que vai ser, você faz um } \\
& \text { projeto e isso deve ser modificado a } \\
& \text { partir do que o pessoal quer, então falta } \\
& \text { mais interação com o pessoal para saber } \\
& \text { o que eles precisam e não só dar o } \\
& \text { produto como eles querem..."; }
\end{aligned}
$$

Roberto Dantas: “Veja bem, é simples e prático, as redes sociais não tem foco hoje nas pessoas, seu foco é em dinheiro e resultados, a pessoa não é um ser humano, é um usuário, para qual quer tipo de indústria on-line, então elas deveriam encarar as pessoas como um ser humano."

\section{Comparativo das Redes Sociais com base nos requisitos levantados}

\subsection{Resultados: Comparativos das Redes So- ciais}

O primeiro passo a ser feito foi levantar um estudo de funcionalidades sobre as redes sociais já citadas, de modo a avaliar de que forma as redes sociais contribuem na formação de um empreendedor, no tocante a facilitações que as mesmas oferecem com suas ferramentas. Visto como dito pelo empreendedor Roberto Dantas (codinome): "Olha, eu tenho um planejamento de marketing pessoal, e todos os dias eu faço alguma coisa em ralação a minha imagem, e as redes sociais são meu único canal para isso; alem de manter contato com o meu público, fazer com que eles me conheçam melhor.".

O estudo das funcionalidades das redes sociais já citadas permitiu a construção da seguinte Tabela 01 : 
Tabela 03: Funcionalidades das redes sociais a serem estudadas

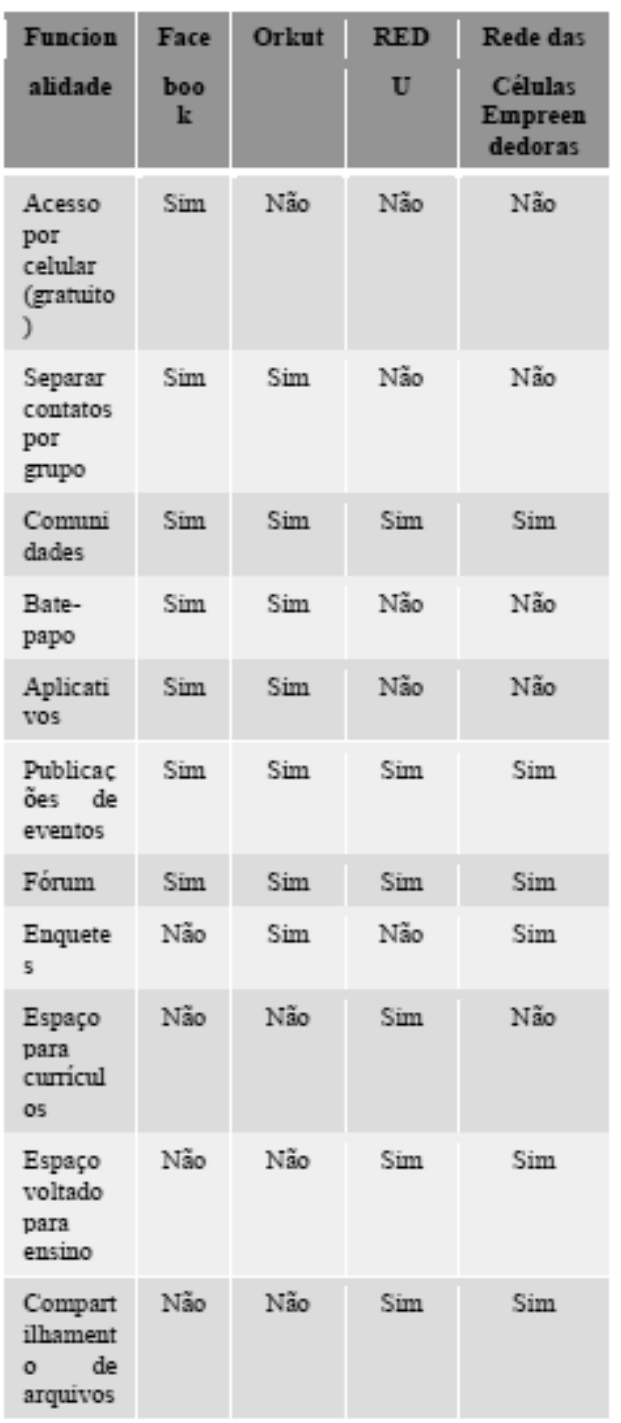

Segundo HIGUERAG, P.R. 1994, a analise qualitativa, no ambiente da engenharia de software, é a análise baseada em experiências e visão subjetiva, tendo isso em mente foi feita uma análise qualitativa com empreendedores quatro empreendedores, cujo seu codinome, sua idade e sua experiência como empreendedor estão descritas na tabela 02 , usando o método da Grounded Theory (Teoria Fundamentada) sobre as redes sociais. E para as redes sociais tem grande relevância como citado: "Olha, eu tenho um planejamento de marketing pessoal, e todos os dias eu faço alguma coisa em ralação a minha imagem, e as redes sociais são meu único canal para isso; alem de manter contato com o meu público, fazer com que eles me conheçam melhor." (Roberto Dantas), "As redes sociais ajudam principalmente na parte de divulgação e marketing, e da imagem, como MySpace, Facebook, Orkut até, foram muito importante quando estava fazendo algumas festas e era só chegar e divulgar no Orkut, e era fácil de conseguir público.”(Armando Passos), “... Eu fiz uma campanha lá, contrate um estagiário, ai eu recebi mais de 600 pessoas dizendo que queriam participar da minha empresa, ou seja, potencializou a minha empresa e muito, porque se eu tivesse feito isso na vida real, teria recebido uns 20 currículos, então potencializa não só nesse âmbito de trazer as pessoas até a sua marca, como também potencializa, em 3 medidas que eu falo, a relação de amor, que as pessoas tem por sua marca, que pode ser você como empreendedor ou sua empresa, tem a relação de defensoria, que seu cliente pode se tornar seu defensor, um bom exemplo disso é que uma cliente que falava muito de mim na internet, muito, todo o dia ela botava um "post" para mim, então o que é que eu fiz, peguei o e-mail dela, peguei o endereço dela e mandei para a casa dela um presente, então ela passou mais um mês falando de mim por causa disso, então você pode usar as redes sociais para descobrir quais são seus clientes em potencial, quem são as pessoas que são defensoras da sua marca, e você pode usar ela para definir um retorno que você está tendo sobre um investimento" (Rodolfo André (codinome)), "na verdade eu uso pouco pra o que eu acho que tem potencial de uso, na verdade eu me limito a usar no tempo curto que eu tenho basicamente o que eu acho que você agrega ao empreendedor é: primeiro, a possibilidade que você tem de investigar o mercado então nas redes sociais você consegue, para determinados segmentos de mercado, você consegue mapear algumas oportunidades existentes e consegue não somente mapear mas identificar se quilo que você está querendo fazer gera negocio ou não, esse é um ponto, outro ponto [...] uma vez diagnosticado que você tem mercado, você poder oferecer em um ambiente de rede social, ou seja, uma vitrine de baixo custo..." (Carlos Ricardo (codinome)) e "A rede social é como um marketing projeta seus sonhos e futuro." (Roberto Dantas). 


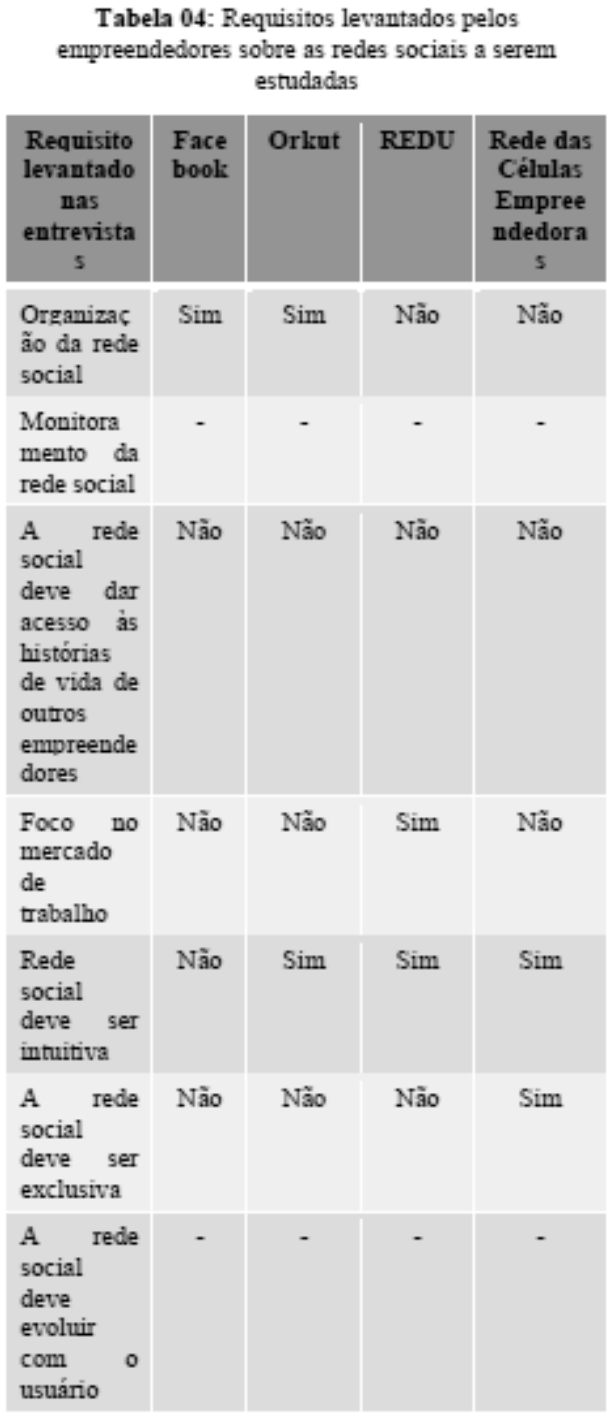

OBS.: o que é representando por (-) não se pode afirmar.

Tendo visto os requisitos levantados nas entrevistas pelos empreendedores, observa-se que o Facebook e o Orkut tem uma organização melhor estruturada do que a REDU e a rede das Células Empreendedoras. Mesmo assim, nenhuma das redes citadas possui uma organização ideal no tocante ao fluxo de informações que o usuário recebe.

Nenhuma rede social tem um campo específico para falar sobre as histórias e experiências de vidas dos participantes. A REDU é a única das rede sociais que se mostra com mais foco no mercado de trabalho dentre as citadas por possuir um campo específico para exibição do currículo do usuário;
Dentre as redes sociais estudadas, a menos intuitiva é o Facebook. No tocante à exclusividade para o publico empreendedor, a rede social das Células Empreendedoras se destaca por ser exclusiva para empreendedores, bem como a REDU que se especializa no público educacional. Já o Facebook e o Orkut não possuem essa qualidade;

\section{Conclusões}

Segundo Emanuel Leite (2000), são as pessoas com um perfil empreendedor que inovam e transformam o mundo ao redor delas, gerando riquezas e desenvolvimento para a comunidade onde moram. Acredita-se que este perfil ou atitude gera também ações inovadoras de melhoria social e ambiental. Ações estas que se fazem tão necessárias para a sustentabilidade e geração de riquezas a longo prazo.

As redes sociais mostram-se como ferramentas eficazes para ajudar os empreendedores a melhorarem ainda mais o contexto social e seu desenvolvimento pessoal. No entanto, poucos estudos existem sobre os benefícios do uso das mídias sociais para a formação de empreendedores.

O presente trabalho apresenta os resultados iniciais de um estudo voltado a trazer indicadores para o desenvolvimento de mídias sociais voltadas a educação empreendedora. Através do mesmo é preciso identificar as potencialidades que as redes sociais possuem para tal propósito, bem como os requisitos necessários para que estas redes possam ser mais eficazes. Ao final o trabalho apresenta um estudo comparativo com as principais redes sociais existentes em relação aos seus benefícios para o empreendedorismo.

O diferencial do trabalho está no uso de uma metodologia de pesquisa qualitativa baseada na Grounded Theory. Significa dizer que os resultados gerados foram obtidos de informações reais obtidas da realidade prática de empreendedores com experiência no mercado. Espera-se que o mesmo sirva de base para futuras pesquisas de desenvolvimento/melhoramento de redes sociais específicas para a formação empreendedora.

Como trabalhos futuros vislumbra-se o obtenção de mais algumas entrevistas, bem como um trabalho mais sistemático nas evidências que levam as comparações entre as redes sociais. Outro ponto está associado à inclusão de novas redes sociais a pesquisa realizada.

\section{Referências}

[1] Cruz Neto, G., Gomes, A., Oliveira, N. (2007): "Aliando Grounded Theory e Re-formulações de conceitos da Teoria da Atividade para o melhor entendimento de práticas humanas". Workshop on 
Perspectives, Challenges and Opportunities for Human-Computer Interaction in Latin America, Rio de Janeiro.

[2] Cruz Neto, G., Gomes, A., Castro, J. (2008):

"Balanceando entre a Sensibilidade a Riqueza do Campo e a Praticidade do Design de Software".IDEAS-2008, Recife.

[3] Cruz Neto, G. (2008): "Estudos qualitativos para elicitação de requisitos: uma abordagem que integra análise sócio-cultural e modelagem organizacional". Tese de Doutorado. CIN/UFPE.

[4] Cruz Neto, G. (2009): “Tecnologia da informação gerando novas oportunidades". Revista FERA. Página 28. Ago/2009.

[5] Cruz Neto, G. (2010): Células Empreendedoras. Escritório de Direitos Autorais. Fundação Biblioteca Nacional. No do Registro: 504.142, Livro: 954, Folha: 368

[6] Dolabela, F. (1999) - Oficina do empreendedor. São Paulo: Cultura.

[7] Dornelas, J. C. A. (2001) - Empreendedorismo: transformando idéias em negócios. Rio de Janeiro: Campus.

[8] GEM 2000: SUMÁRIO EXECUTIVO. Publicado em: http://www.gemconsortium.org/download/1316206345780/Empreended

rismo\%20no\%20Brasil $\% 202000$.pdf

, acessado dia 10/01/2011 às 15:00

[9] Giardelli, G. (2010): A era da generosidade e criatividade coletiva. HSM online (www.gilgiardelli.com.br).

[10] HIGUERAG, P.R. 1994. An Introduction to Team Risk Management, Technical Leite, E. F.(2000): O Fenômeno do Empreendedorismo. Editora Bagaço.

[11] Leite, E. (2002): O fenômeno do empreendedorismo criando riquezas. Ed. Revista e ampliada, editora bagaço 2002 pag. 37 - 49 )

[12] Machado, J. R.; Tijiboy, A. V.;(2005): Redes Sociais Virtuais: um espaço para efetivação da aprendizagem cooperativa. Novas tecnologias na educação. CINTED-UFRGS. V. 3 No 1.
[13] MARIANO, Sandra R. H. Empreendedorismo e inovação: criatividade e attitude empreendedora/ Sandra RH Mariano; Verônica Feder Mayer - Rio de Janeiro. Fundação CECIERJ, 2008. Pag. 215 217

[14] SEBRAE (2011): Características do Empreendedor. Publicado em http://www.sebrae.com.br/customizado/desenvolvi mento-territorial/o-quee/empreendedorismo/integra_bia?ident_unico=336,

acessado dia 19/03/2011 às 10: 45 a.m.

[15] SEBRAE 2005: Brasil é ruim para fazer negócios, diz Bird. Publicado em: http://www.sebraesc. com.br/newart/default.asp?materia $=10259$,

acessado dia 10/01/2011 às 14:00 P.M.

[16] Strauss e Corbin (1990,1a ed.;1998, 2a ed.): $B a-$ sics of Qualitative Research: Techniques and procedures for developing grounded theory. Sage. Report. Software Engineering Institute, Carnegie Mellon University. USA. 